\title{
Does Permeability Promote Social Cohesion
}

\author{
Aldrin Abdullah', Massoomeh Hedayati Marzbali2, \\ Mohammad Javad Maghsoodi Tilaki ${ }^{3}$, Azizi Bahauddin ${ }^{1}$ \\ 1School of Housing, Building \& Planning, Universiti Sains Malaysia, Penang, Malaysia \\ 2Department of Architecture, Ayatollah Amoli Branch, Islamic Azad University, Amol, Iran \\ ${ }^{3}$ School of Humanities, University Sains Malaysia, Penang, Malaysia \\ aldrin@usm.my
}

\begin{abstract}
Understanding environmental conditions of neighbourhoods can play a critical role in maintaining social interactions among residents. This research is carried out to assess the effect of street permeability on the degree of social cohesion among residents in a residential neighbourhood in Penang, Malaysia. A total of 250 households participated in the study. The findings indicate that permeability can account for a significant proportion of the variance in residents' social cohesion. Residents living in less permeable streets are more likely to have a high social cohesion with their neighbours. The results further support the defensible space concept which advocates closed streets.
\end{abstract}

Keywords: Permeability; social cohesion; road type; residential neighbourhood

elSSN 2398-4295 @ 2018. The Authors. Published for AMER ABRA cE-Bs by e-International Publishing House, Ltd., UK. This is an open-access article under the CC BY-NC-ND license (http://creativecommons.org/licenses/bync-nd/4.0/). Peer-review under responsibility of AMER (Association of Malaysian Environment-Behaviour Researchers), ABRA (Association of Behavioural Researchers on Asians) and cE-Bs (Centre for EnvironmentBehaviour Studies), Faculty of Architecture, Planning \& Surveying, Universiti Teknologi MARA, Malaysia.

DOI: http://dx.doi.org/10.21834/ajbes.v3i10.83 


\subsection{Introduction}

There is no doubt that both social and physical factors have an effect on human behaviour. Without denying the effect of social factors, there is a need to examine more closely the physical factors that may contribute to social interaction. It is anticipated that the patterns of neighbourhood layout contribute to facilitating or disrupting any sense of attachment among residents. Although most planning literature has spoken of the enhancement of cohesion and privacy on cul-de-sacs rather than through roads, there is little evidence to support this assumption (Abdullah et al., 2015; Brown \& Werner, 1985). The question arises in which physical characteristics of urban environments contribute to facilitating social interactions among neighbours. Our primary interest here is the influence of community design on social cohesion in an urban neighbourhood in Malaysia. One of the pathways through which aspects of the built environment might affect residents' health and safety is neighbourhood layout (Hedayati Marzbali et al., 2016; Ziegler, 2007). This is an interesting realisation of the urban planners that the design of the built environment plays a significant role in human behaviour. Finding ways to facilitate social interactions may be especially important in Malaysia which is composed of different ethnic backgrounds. Malaysia is a multiracial, multicultural and multi-religious country with the majority of the population embracing Islam, Buddhism, Hinduism and Christianity. Therefore, understanding the patterns of social cohesion among this multiracial society could bring new insights that could facilitate racial integration.

An overview of the existing literature indicates that there are two quite divergent views on the pattern of street layout among urban planners. First of all, Jacobs (1961) in her well known discussion of crime and urban neighbourhood claims that the use of street sidewalk that brings in more outsiders is a bedrock feature of a safe city. Secondly, contrary to Jacobs, the proponents of Newman's (1972) defensible space concept demonstrate their advocacy towards cul-de-sac streets. Due to the above dispute on the role of permeability in relation to social cohesion, this study seeks to address this issue in the Malaysian context. Besides limited empirical studies on the relationship between design features and social cohesion, previous studies have only examined street pattern differences in terms of victims' experiences and burglary distribution, particularly in the European context (Shu, 2009) and the focus is not given on people's perception of surrounding environment that influences their quality of life (Beavon et al., 1994; Shu, 2009). The current study addresses this shortcoming in the literature by testing the impact of permeability indicators on social cohesion. In doing so, this study examines whether social cohesion differs across road types. These discussions lead to the following hypotheses as shown on a hypothesised model (see Figure 1).

$\mathrm{H1}$. The five indicators of social cohesion provide a valid measurement of the social cohesion construct.

$\mathrm{H} 2$. There is a significant relationship between the indicators of street permeability and social cohesion.

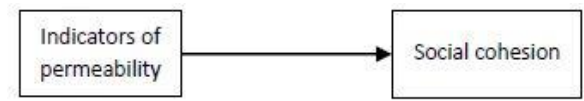

Figure 1: The conceptual pathway between street permeability and social cohesion 


\subsection{Literature Review}

\section{Community design and human behaviour}

Evidence suggests that the spatial layout of street networks plays a vital role in establishing people's utilisation of places and movements (Johnson \& Bowers, 2010). There are two different perspectives on the patterns of neighbourhood layout. Firstly, Newman and Poyner deem passers-by as potential offenders who should be expelled from residential areas. Newman (1972) explored important perspectives about human behaviour in the urban environment and encouraged less permeable layouts. Contrary to the position of a territoriality-based defensible space system advised by Newman (1972), Jacobs and Hillier consider passing strangers as being often generated by the intelligible through the street system. Referring to diverse, open and permeable land uses, there is a more continual flow of people which can be referred to what Jacobs presents as "a basic supply of activities and eyes" (Jacobs, 1961, p. 40). While through-roads with front entrances on both sides make spaces safer, fewer line neighbours, segregation and cul-de-sac patterns are the factors that make spaces quite vulnerable (Shu, 1999). Indeed, those anonymous streets that Newman defines more vulnerable are instead considered by Shu as safer patterns.

A recent study by Shu (2009) proposes that segregated streets become extremely vulnerable when associated with low inter-visibility in the areas while streets with higher accessibility are very safe when combined with higher inter-visibility and informal surveillance. However, on the whole, researchers with viewpoints similar to Jacobs have found that busier streets with some pedestrian movements are associated with high social interactions and low crime rates. To look at both sides of the continuum, similar to Jacobs' eyes on the street concept, New Urbanists believe that strangers are the sources of safety while the proponents of defensible space consider strangers as the source of danger (Hillier, 2004). However, it should be noted that the context in which Jacobs and Newman's studies operate may be the influencing factor. Jacobs (1961) has drawn attention to the urban design and narrowed the investigation area of crime-space studies. Her study is more concerned with macro-scale planning such as commercial and business settings while Newman's work focuses on micro-scale settings such as public housing and residential settings.

\section{Permeability and social cohesion}

Although few studies have focused on the relationship between social cohesion and road type, a review of the literature has shown some mixed findings. Evidence seems to suggest that there is a high degree of neighbouring behaviour on cul-de-sacs (Brown \& Werner, 1985). Similarly, a previous study has indicated that residents living on high permeable streets have limited their activities in the use of property frontage and their exposure to the strangers (Appleyard \& Lintell, 1972). The findings of Mayo's (1979) study challenge some of the present beliefs that manipulation of the streets can provide a better social atmosphere of streets within a neighbourhood. While a number of studies have found a significant relationship between street form and neighbouring behaviour (Hillier, 2004), scholars such as Mayo (1979) claim that no element in the site plan is influential in friendship ties. Mayo 
reports that planners cannot directly influence behaviour through the manipulation of street forms.

\subsection{Methodology}

\section{Study Context}

This study was conducted in a typical residential neighbourhood in Penang, Malaysia. The study was quantitative in nature and involved asking the residents to answer a survey faceto-face. The survey contained several sections aiming at ascertaining the background information of the respondents and their perceived social integration. A sampling framework was developed from the list of all of the landed properties in the study area. The respondents were selected using a systematic sampling method with a random start. In all, 250 residents participated in the survey. Of these respondents, 108 were male (43\%), and 142 were female $(57 \%)$ with an average age of 53 years $(S D=12.98)$. The survey further illustrates that $51 \%$ of the respondents were Malay, $39 \%$ were Chinese and $10 \%$ were Indian.

\section{Measures}

\section{Permeability}

To capture the degree of street permeability, we developed four indicators that were adapted based on previous works. First, road type refers to the degree of road hierarchy (Shu, 2009) as defined by Public Works Department Malaysia (PWD). This variable consists of five categories, namely U1 (cul-de-sacs), U2 (local streets), U3 (minor collector), U4 (major collector) and U5 (arterial). The second spatial indicator is street accessibility which is adapted based on the work of Beavon et al. (1994) and Johnson and Brower (2010). It focuses on the degree of street accessibility by examining the number of turns into the street segment, in which a larger number indicates greater degrees of accessibility. The third indicator is traffic flow that represents traffic movement through neighbourhood streets. Since traffic information based on each street segment was not available, this item was measured based on the author's judgement by on-site observation. The last indicator, constitutedness, is related to the degree of inter-visibility which means a front door-to-front door relationship to measure the degree of inter-visibility between houses on both sides of each street segment. This indicator is adapted from the work of Shu (2009).

\section{Social cohesion}

Social cohesion was measured by asking the respondents to report on their own feelings of cohesion. This variable represents the extent to which respondents like the neighbourhood and share similar interests. The items were adapted based on the work of Sampson et al. (1997). The items were: (1) people around here are willing to help their neighbours; (2) This is a close-knit neighbourhood; (3) People in this neighbourhood can be trusted; (4) People in this neighbourhood get along with each other; and (5) People in this neighbourhood share 
the same values. The responses were recorded on a 7-point scale with 1 representing 'strongly agree' and 7 representing 'strongly disagree'.

\subsection{Findings}

Responses to the seven-point Likert scales were aggregated to the household level as initial measures. The five social cohesion statements were examined for validity and reliability based on the index of Cronbach's Alpha (a). The results of the validity and reliability tests are illustrated in Table 1, indicating that each item had a corrected item-to-scale correlation above 0.3 ( 0.87 to 0.93 ). The Cronbach's a score for social cohesion ( $\alpha=0.97)$ was higher than the recommended 0.70 cut-off value (Nunnally \& Bernstein, 1994) and it indicated good scale reliability. The findings reveal that the five items were valid and reliable to measure the social cohesion construct. Therefore, $\mathrm{H} 1$ is supported. The next test is to examine the mean differences of social cohesion based on different road types. The data were analysed using the one-way ANOVA to determine the significant differences in the mean of social cohesion. The results reveal that there are significant mean differences between road types $(F(5$, 244) $=4.057, p<0.01)$. As shown in Table 1, the results indicate that residents living in cul-desacs street pattern perceived the highest level of social cohesion, whereas those living in arterials (through roads) perceived the lowest level of social cohesion. The findings of the present study indicate that respondents from the properties located on cul-de-sacs and local streets perceived a higher level of social cohesion compared to those from the arterials. This result is consistent with the findings of a previous study (Brown \& Werner, 1985), suggesting that residents from close streets are more protective of their surroundings and are associated with higher levels neighbourhood cohesion, compared to the higher levels of hierarchy.

Table 1: Descriptive statistics, reliability and item-total statistics for neighbourhood cohesion items

\begin{tabular}{|c|c|c|c|c|c|c|c|}
\hline \multirow[t]{2}{*}{ Variable } & \multicolumn{3}{|c|}{ Social cohesion $(\mathrm{N}=250)$} & \multirow[t]{2}{*}{ Variable } & \multirow{2}{*}{$\begin{array}{l}\text { Corrected } \\
\text { Item-Total } \\
\text { Correlation } \\
\end{array}$} & \multirow{2}{*}{$\begin{array}{l}\text { Cronbach's } \\
\text { Alpha if Item } \\
\text { Deleted }\end{array}$} & \multirow{2}{*}{$\begin{array}{l}\text { One-way } \\
\text { ANOVA }\end{array}$} \\
\hline & Groups & Mean & $S D$ & & & & \\
\hline \multirow[t]{5}{*}{ Road type } & $\mathrm{U} 1$ & 20.51 & 4.164 & Cohesion 1 & 0.87 & 0.97 & \multirow[t]{5}{*}{$\begin{array}{l}4.057^{* *} \\
p<0.01\end{array}$} \\
\hline & U2 & 19.85 & 4.202 & Cohesion 2 & 0.90 & & \\
\hline & U3 & 19.38 & 4.340 & Cohesion 3 & 0.91 & & \\
\hline & U4 & 18.33 & 4.455 & Cohesion 4 & 0.93 & & \\
\hline & U5 & 17.80 & 3.851 & Cohesion 5 & 0.91 & & \\
\hline
\end{tabular}

Bivariate correlations. Road type has demonstrated a statistically significant negative correlation with social cohesion $(r=-.221, p<0.01)$. Consistent with theoretical expectations, we find that street accessibility carries a significant relationship with social cohesion. However, this relationship is negative $(r=-.122, p<0.05)$, indicating that high accessibility is associated with low social cohesion. The level of social cohesion was highest in streets with less accessibility (one-turn) and lowest in streets with high accessibility (six-turn). In addition to these two variables, traffic flow carried significant relationship with social cohesion ( $r=-$ 
$.214, p<0.05)$. However, there is no significant correlation between the degree of constitutedness and social cohesion $(r=.043, p>0.05)$. In sum, the results of this study indicate that high levels of permeability indicators are associated with low levels of perceptions of cohesion among residents. Therefore, the second research hypothesis is partly supported.

The result further indicates the positive and significant relationships between road type, street accessibility and traffic flow. This demonstrates low levels of accessibility and traffic flow at the lowest level of the hierarchy (cul-de-sac streets). However, there are negative correlations between the degree of constitutedness and road type $(r=-.219, p<0.01)$ and traffic flow $(r=-199, p<0.01)$. This suggests that constituted areas, which exhibit strong front door-to-front door inter-visibility, are cul-de-sac street patterns. This could be due to the good number of houses on cul-de-sacs. Houses located in the areas with high traffic flow tend to have less degrees of inter-visibility than those situated in areas known to have low traffic flow.

\subsection{Discussions}

Neighbourhood characteristics contribute to the level of social integration among residents. In fact, the design of neighbourhood layout should foster good social interactions and relationship between residents. Nonetheless, new developments as can be seen in urban areas tend to create barriers to the users. The question we face today lies in which combination of spatial circumstances is best for social interactions and provides security for urban residents. Thus, if the street form can encourage or discourage social interactions, then these patterns should differ among different levels of permeability. The purpose of this study is to assess the impact of street permeability on social interactions among residents in an urban neighbourhood in Penang, Malaysia. We have found that residents living in the culde-sac street pattern perceived higher levels of social cohesion than their counterparts living on other road hierarchies. This is consistent with the findings of the work of Brown and Werner (1985), where cul-de-sac road types are associated with high levels of social cohesion. Given the methodological differences between the two studies, the consistency of results adds strengths to our finding that residents in cul-de-sacs indeed perceived high levels of neighbourhood attachment. Likewise, we have come to the negative and significant correlations between permeability and social cohesion, in which high permeability is associated with low levels of social cohesion.

Some limitations and suggestions for future research are worth noting. Research has suggested that residential stability affects local friendship and participations in the society (Abdullah et al., 2013). Our study does not include residents' background in the analysis. Further investigation on the impact of social factors on perceptions of cohesion is warranted. Likewise, we are aware that there are many other physical factors that could have some influences on the degree of social cohesion. Therefore, another aspect to be cautioned when interpreting the result is that, one should consider the whole spatial system of a neighbourhood layout. 
Therefore, the evidence suggests high degrees of cohesiveness and privacy on cul-desacs street types than through roads. This is in line with Newman's defensible space, which bring an environment under the control of its inhabitants. However, such design, although very much disliked by international housing experts (particularly in the UK) (Hillier, 2004, p. 32), was in fact conducive to the facilitation of social interactions among neighbours. One possible way to address this would be to avoid major roads which pass through the neighbourhood- a consideration that should be given by professionals. Our larger point, however, is that enhancing social cohesion, as the urban policy being focused, could bring about many positive, worthwhile effects.

\section{Acknowledgement}

The authors would like to thank the Universiti Sains Malaysia (USM) for providing financial support for this study.

\section{References}

Abdullah, A., Hedayati Marzbali, M., Woolley, H., Bahauddin, A., \& Maliki, N. Z. (2014). Testing for Individual Factors for the Fear of Crime Using a Multiple Indicator-Multiple Cause Model. European Journal on Criminal Policy and Research, 20(1), 1-22.

Abdullah, A., Hedayati Marzbali, M., Tilaki, M. J. M., \& Bahauddin, A. (2015). The Influence of Permeability on Social Cohesion: Is it Good or Bad? Procedia-Social and Behavioral Sciences, 168, 261-269.

Appleyard, D., \& Lintell, M. (1972). The environmental quality of city streets: the residents' viewpoint. Journal of the American Institute of Planners, 38(2), 84-101.

Beavon, D. J. K., Brantingham, P. L., \& Brantingham, P. J. (1994). The influence of street networks on the patterning of property offenses. Crime prevention studies, 2, 115-148.

Brown, B. B., \& Werner, C. M. (1985). Social cohesiveness, territoriality, and holiday decorations: The influence of cul-de-sacs. Environment and behavior, 17(5), 539-565.

Greenberg, S. W., \& Rohe, W. M. (1984). Neighbourhood design and crime: a tale of two perspectives. Journal of the American Planning Association, 50(1), 48-61.

Hedayati Marzbali, M., Abdullah, A., \& Maghsoodi Tilaki, M. J. (2016). The effectiveness of interventions in the built environment for improving health by addressing fear of crime. International Journal of Law, Crime and Justice. doi:10.1016/j.jilcj.2015.12.002.

Hillier, B. (2004). Can streets be made safe? Urban Design International, 9(1), 31-45.

Jacobs, J. (1961). The Death and Life of Great American Cities. New York: Random House.

Johnson, S. D., \& Bowers, K. J. (2010). Permeability and Burglary Risk: Are Cul-de-Sacs Safer? Journal of Quantitative Criminology, 26(1), 89-111. 
Mayo, J. M. (1979). Effects of street forms on suburban neighboring behavior. Environment and behavior, 11(3), 375-397.

Morrow-Jones, H. A., Irwin, E. G., \& Roe, B. (2004). Consumer preference for neotraditional neighborhood characteristics. HOUSING POLICY DEBATE-WASHINGTON-, 15(1), 171-202.

Newman, O. (1972). Defensible space; crime prevention through urban design New York: Macmillan.

Nunnally, J. C., \& Bernstein, I. H. (1994). Psychometric theory (3rd ed.). New York: McGraw-Hill.

Poyner, B. (1983). Designing against Crime: Beyond Defensible Space. London: Butterworths.

Sampson, R. J., Raudenbush, S. W., \& Earls, F. (1997). Neighborhoods and violent crime: A multilevel study of collective efficacy. Science, 277(5328), 918-924.

Shu, C. F. (1999). Housing Layout and Crime Vulnerability. Paper presented at the Space Syntax Second International Symposium, Brasilia, Brazil.

Shu, C. F. (2009). Spatial Configuration of Residential Area and Vulnerability of Burglary: Case Studies from UK and Taiwan. Paper presented at the 7th International Space Syntax Symposium, Stockholm.

Ziegler, E. H. (2007). American Cities, Urban Planning, and Place Based Crime Prevetion. Paper presented at the pantheon sorbonne university of paris 1 , France, Paris. 